\title{
CATALYTIC ACTIVITY OF COBALT PHOSPHATE TREATED WITH HYDROGEN: HYDROGENATION OF 1,3-BUTADIENE
}

\author{
NORIYASU OKAZAKI, FUMIO ISHIDA, YUKITO UCHIMURA, YUZO IMIZU ${ }^{\dagger}$, \\ and AKIO TADA \\ Department of Applied and Environmental Chemistry, Kitami Institute of Technology, \\ Kitami, Hokkaido, 090-8507 Japan \\ $\dagger$ Department of Materials Science, Kitami Institute of Technology, Kitami, Hokkaido, \\ 090-8507 Japan
}

\begin{abstract}
Cobalt phosphate showed catalytic activity for the title reaction, only when it was treated with hydrogen. The activity depended on its hydrogen-treatment temperature and reached a maximum at $550{ }^{\circ} \mathrm{C}$. The hydrogenation of 1,3-butadiene over hydrogen-treated cobalt phosphate produced selectively butene with a preferential percentage of 1-butene even at a high temperature.
\end{abstract}

\section{INTRODUCTION}

Metal phosphates have been investigated extensively as solid catalysts ${ }^{1,2}$, but their catalytic activity has been evaluated exclusively for acid-catalyzed reactions ${ }^{1-8}$. Phosphates seem to be potential catalyst materials, but their utility as catalysts is not extensively recognized. When they are properly pretreated, they will exhibit catalytic activity for a variety of reactions. For example, some phosphates could be active for oxidation or reduction, when they are treated in oxidativ e or reductive atmosphere. However, such attempts have never been made so far. Consequently, no catalytic functions other than acidic function have been developed. The present study was undertaken to explore new catalytic functions of cobalt phosphate treated with hydrogen.

\section{EXPERIMENTAL}

\section{Cobalt phosphate}

Cobalt phosphate, $\mathrm{Co}_{3}\left(\mathrm{PO}_{4}\right)_{2} \times \mathrm{xH}_{2} \mathrm{O}$ (reagent grade), was of Kanto Chemical Co., 
and was used as it is. Cobalt phosphate (powder) was pressed in tablets, followed by crushing and sieving (16-32 mesh).

\section{$\underline{\text { Reaction }}$}

A recirculation-type reaction apparatus (reactor volume $=410 \mathrm{~cm}^{3}$ ) was used to carry out the title reaction. The initial pressures of 1,3-butadiene and hydrogen were 100 and 300 Torr, respectively. A $0.30 \mathrm{~g}$ of grained cobalt phosphate was packed with quartz wool plugs in a U-shaped quartz tube $(0.6 \mathrm{~cm}$ inner diameter, $60 \mathrm{~cm}$ length $)$ of the reactor, and then evacuated for $3 \mathrm{~h}$ at a specified temperature followed by heating in hydrogen for $3 \mathrm{~h}$ at the same temperature as the evacuation temperature, prior to the reaction. The gaseous products were analyzed gaschromatographically using DMS column $\left(20^{\circ} \mathrm{C}\right)$.

\section{RESULTS AND DISCUSSION}

\section{Characterization of cobalt phosphate treated with hydrogen}

\section{Hydrogen consumption}

Figure 1 depicts the amount of hydrogen consumed for the hydrogen-treatment of cobalt phosphate at various temperatures as a function of treatment time. Below $450^{\circ} \mathrm{C}$ no reduction occurred. The hydrogen consumption started at nearly $450^{\circ} \mathrm{C}$ and its rate increased with increases in hydrogen-treatment temperature up to $700{ }^{\circ} \mathrm{C}$.

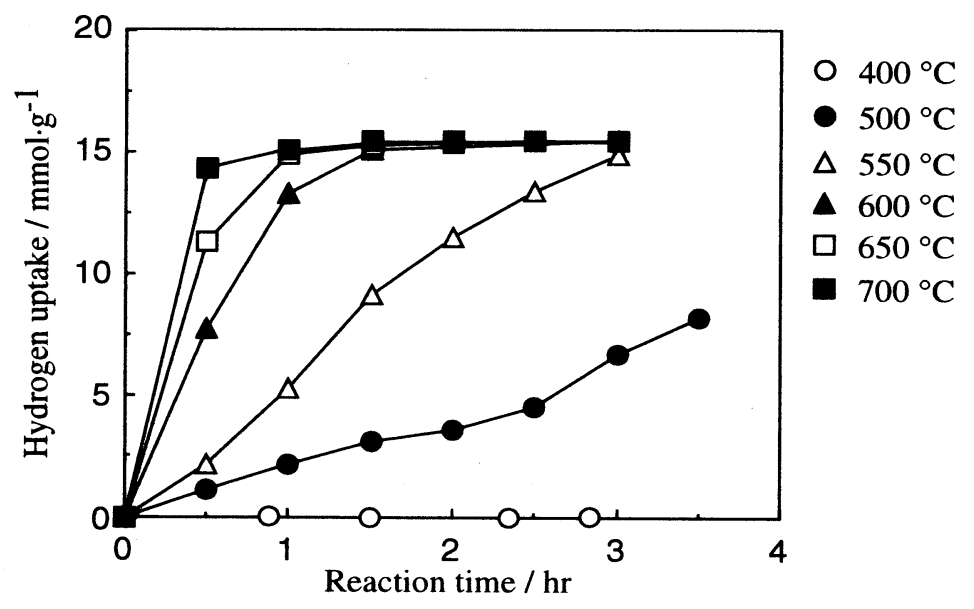

FIGURE 1 Hydrogen-treatment of cobalt phosphate at various temperatures. 


\section{$\underline{\text { XRD, BET surface area }}$}

The X-ray diffraction measurements were made on hydrogen-treated cobalt phosphate in order to get information about their resulting materials. However, no diffraction lines were observed for all samples with hydrogentreatment temperature of 450 $650{ }^{\circ} \mathrm{C}$, suggesting the formation of neither large cobalt crystallites nor cobalt phosphide crystallites. The BET surface areas of samples with hydrogentreatment temperature of 450 $650{ }^{\circ} \mathrm{C}$ were below $1 \mathrm{~m}^{2} \cdot \mathrm{g}^{-1}$.

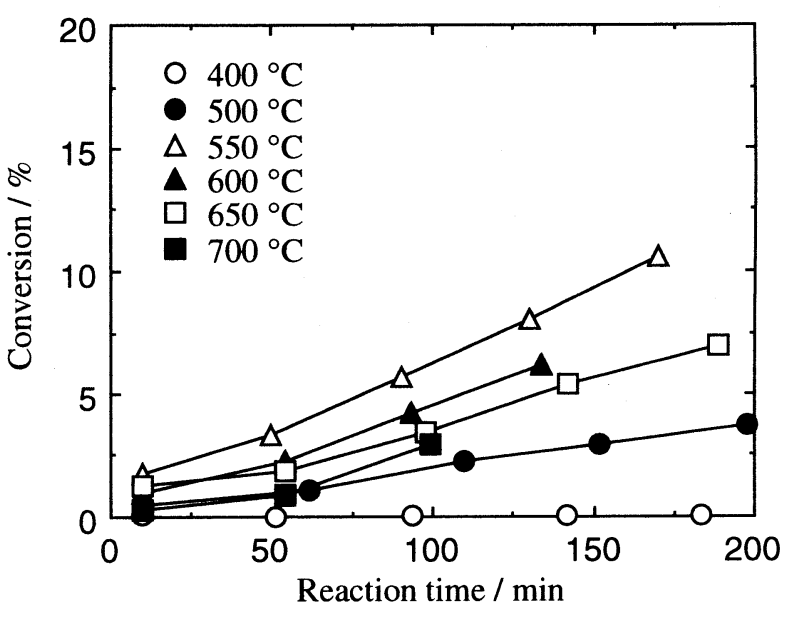

FIGURE 2 Activity of cobalt phosphates with different hydrogen-treatment temperatures for 1,3-butadiene hydrogenation at $100{ }^{\circ} \mathrm{C}$.

\section{Effect of hydrogen-treatment temperature on catalytic activity}

Figure 2 shows the time courses of 1,3 -butadiene hydrogenation at $100^{\circ} \mathrm{C}$ over cobalt phosphate catalysts with different hydrogen-treatment temperatures. In general, 1,3butadiene conversion increased almost proportionally with increasing reaction time up to $200 \mathrm{~min}$ for all catalysts. Below $400^{\circ} \mathrm{C}$, no catalytic activity was observed. The activity appeared when cobalt phosphate was treated at $500^{\circ} \mathrm{C}$, reached a maximum at $550{ }^{\circ} \mathrm{C}$, and then decreased. In the hydrogenation of 1,3-butadiene, it can be first converted into butene (partially hydrogenated product), and then, converted into butane (completely hydrogenated product). In the partial hydrogenation, both 1,2-addition and 1, 4-addition of two hydrogen atoms can occur at the 1,2- and 1, 4-carbon positions, giving 1-butene (1,2-addition) and 2-butene (1, 4-addition), respectively. And at the same time, three butene isomers (1-, trans-2-, and cis-2-butenes) are allowed to isomerize. Therefore, the product distributions over hydrogen-treated cobalt phosphate catalysts will reflect their catalytic features. On hydrogen-treatment at $550{ }^{\circ} \mathrm{C}$, where the reduction of cobalt phosphate was not complete (Figure 1), the activity reached a maximum. This indicates that incomplete reduction is favorable for generating active sites. On the basis of the amount of hydrogen consumed up to $550{ }^{\circ} \mathrm{C}$, the Co species of cobalt phosphate treated at $550{ }^{\circ} \mathrm{C}$ are conjectured to be a 
mixture of $\mathrm{Co}$ and $\mathrm{CoP}_{\mathrm{x}}$.

Figure 3 shows the product distribution of 1,3butadiene hydrogenation at $100{ }^{\circ} \mathrm{C}$ as a function of reaction time for cobalt phosphate treated at $550^{\circ} \mathrm{C}$. Butene was mainly formed with the composition in the order: 1-butene > trans-2-butene >cis-2butene. It is noted that the product distribution remained almost unchanged with reaction time.

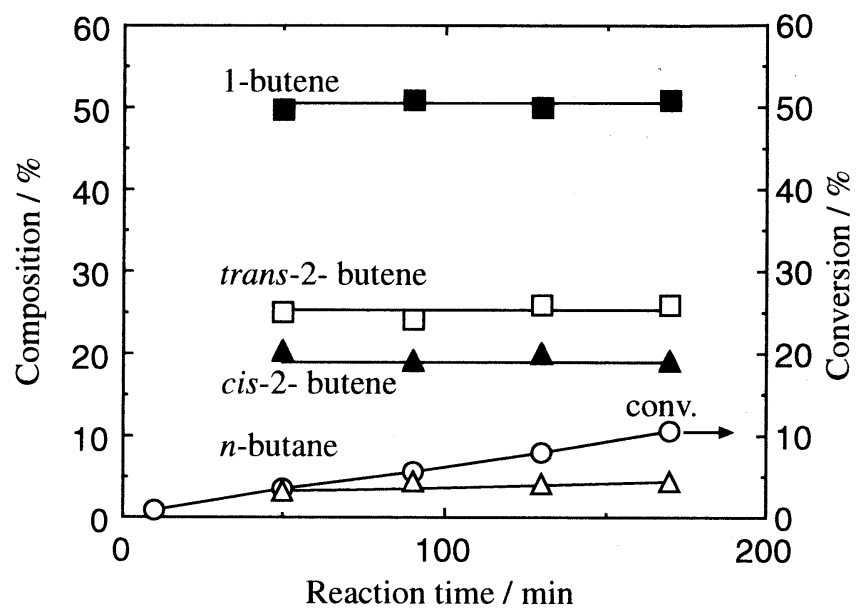

FIGURE 3 Product distribution of 1,3-butadiene hydrogenation at $100^{\circ} \mathrm{C}$ as a function of reaction time for cobalt phosphate hydrogen-treatmented at $550{ }^{\circ} \mathrm{C}$.

Table 1 lists the products of the reaction at $100^{\circ} \mathrm{C}$ over other cobalt phosphate catalysts

TABLE 1 Reaction products at $100^{\circ} \mathrm{C}$ for cobalt phosphates treaed with hydrogen at various temperatures except for $550^{\circ} \mathrm{C}$

\begin{tabular}{|c|c|c|c|c|c|c|}
\hline \multicolumn{2}{|c|}{ Reduc. temp. Reac. time } & \multirow{2}{*}{$\begin{array}{c}\text { Conv. } \\
/ \% \\
\end{array}$} & \multicolumn{4}{|c|}{ Composition / \% } \\
\hline $1{ }^{\circ} \mathrm{C}$ & $/ \min$ & & 1-butene & trans-2-butene & cis-2-butene & $n$-butane \\
\hline \multirow[t]{4}{*}{500} & 62 & 1.2 & 51 & 25 & 15 & 9 \\
\hline & 110 & 2.0 & 49 & 26 & 18 & 7 \\
\hline & 155 & 2.9 & 51 & 23 & 19 & 7 \\
\hline & 198 & 3.7 & 50 & 24 & 20 & 6 \\
\hline \multirow[t]{4}{*}{600} & 54 & 2.7 & 49 & 22 & 21 & 8 \\
\hline & 94 & 4.5 & 48 & 23 & 23 & 6 \\
\hline & 114 & 6.2 & 48 & 24 & 22 & 6 \\
\hline & 174 & 7.1 & 48 & 24 & 22 & 6 \\
\hline \multirow[t]{4}{*}{650} & 54 & 0.9 & 52 & 22 & 19 & 7 \\
\hline & 98 & 3.5 & 53 & 23 & 17 & 7 \\
\hline & 142 & 5.5 & 50 & 24 & 20 & 6 \\
\hline & 188 & 6.9 & 52 & 23 & 19 & 6 \\
\hline \multirow[t]{4}{*}{700} & 54 & 1.0 & 50 & 24 & 18 & 8 \\
\hline & 98 & 2.5 & 50 & 23 & 19 & 8 \\
\hline & 142 & - & 51 & 24 & 19 & 6 \\
\hline & 188 & - & 50 & 23 & 20 & 7 \\
\hline
\end{tabular}


with various reduction temperatures. Apparently, the product distributions are quite similar one another regardless of hydrogen-treatment temperature, suggesting that the surface properties of cobalt phosphate treated at $500-700^{\circ} \mathrm{C}$ are nearly the same in quality. In addition, the product distributions did not depend on reaction time. The constancy of the ratio of butane to butene means that the primary product (butene) can hardly react with hydrogen to produce

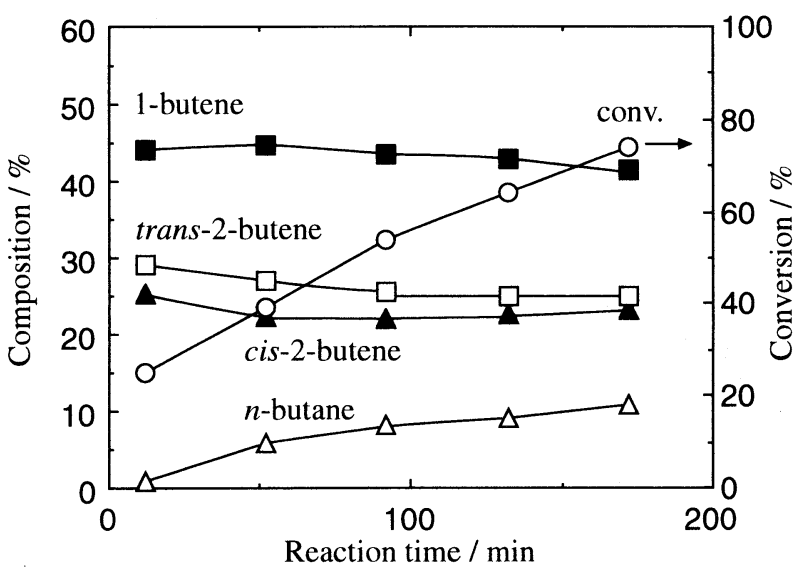

FIGURE 4 Product distribution of 1,3-butadiene hydrogenation at $150^{\circ} \mathrm{C}$ as a function of reaction time for cobalt phosphate hydrogen-treatmented at $550{ }^{\circ} \mathrm{C}$.

\section{butane. Moreover, the constancy}

of the ratio of 1-butene to 2-butene means that the primary product (1-butene) does not have enough opportunity for isomerizing. These results will be related to such a situation that the catalyst surface is covered by a large amount of 1,3-butadiene; the amount of hydrogen or butene adsorbed is very small. If the butene isomerization rate is negligible, the composition of butene depends on the ease of 1,2-addition or 1,3-addition. The above results indicate that 1,2 -addition preferentially occurs over hydrogen-treated cobalt phosphate. This will be due to the difficulty of the dissociation of hydrogen molecule and that of the surface movement of the resulting hydrogen atoms.

\section{Effect of reaction temperature on catalytic activity and selectivity}

The conversion and product distribution for the reaction at $150{ }^{\circ} \mathrm{C}$ over cobalt phosphate treated at $550^{\circ} \mathrm{C}$ (Figure 4) were different from those at $100{ }^{\circ} \mathrm{C}$ (Figure 3). The conversion greatly increased, and as a result, the percentage of butane became much higher. As to the composition of butene, slightly, 1-butene decreased and conversely 2-butene increased. These results indicate that with an increase in reaction temperature, the unique catalytic features of hydrogen-treated cobalt phosphate became weak. This can be explained as follows: since at a higher reaction temperature the coverage of 1,3-butadiene becomes small, molecular hydrogen readily dissociates, and atomic hydrogens become mobile. The increase in content of 2-butene will be caused by the enhancement of 1,3-addition as well 
as the isomerization of 1-butene. The product distribution over cobalt phosphate treated at $650{ }^{\circ} \mathrm{C}$ was almost the same as that for cobalt phosphate treated at $550{ }^{\circ} \mathrm{C}$ (not shown).

\section{CONCLUSION}

(1) Hydrogen-treated cobalt phosphate was catalytically active for the hydrogenation of 1,3-butadiene: the activity reached a maximum on hydrogen-treatment at $550{ }^{\circ} \mathrm{C}$.

(2) The hydrogenation of 1,3-butadiene over hydrogen-treated cobalt phosphates produced selectively butene with a preferential percentage of 1-butene even at a high temperature.

\section{REFERENCES}

1. J. B. Moffat, Catal. Rev. -SCI. ENG., 18, 199 (1978).

2. J. B. Moffat, in Toppics in Phosphorus Chemistry, edited by M. Grayson and E. J. Griffith (Wiley-Interscience, New York, 1980), Vol. 10, p. 285.

3. H. Itoh, A. Tada, and K. Tanabe, Chem. Lett., 1567 (1981).

4. H. Itoh, A. Tada, and H. Hattori, J. Catal., 76, 235 (1982).

5. H. Itoh, A. Tada, and H. Hattori, ibid., 80, 494 (1983).

6. Y. Imizu, S. Aoyama, H. Itoh, and A. Tada, Chem. Lett., 1455 (1981).

7. K. Segawa, S. Nakata, and S. Asaoka, Mat. Chem. Phys., 17, 181 (1987).

8. A. Tada, Mat. Chem. Phys., 17, 145 (1987). 